\title{
SÍNDROME DE FOURNIER: A PERCEPÇAO DO SEU PORTADOR
}

\author{
THE PERCEPTION OF THE FOURNIER SYNDROME'S PATIENT
}

\section{SÍNDROME DE FOURNIER: LA PERCEPCIÓN DE SU PORTADOR}

\author{
Fernanda Cavalini * \\ Tokico Murakawa Moriya** \\ Nilza Teresa Rotter Pelei**
}

Cavalini F, Moriya TM, Pelá NTR. Síndrome de Fournier: a percepção do seu portador. Rev Esc Enferm USP 2002; 36(2): 108-14.

\section{RESUMO}

O propósito da presente investigação foi identificar a percepção dos pacientes que tiveram Sindrome de Fournier (SF) sobre esta afecção, bem como sobre seus cuidadores. Os dados foram coletados através de entrevista com roteiro estruturado e a análise baseada na Análise de Prosa de André. Segundo os entrevistados, a SF causa dor intensa, edema, febre e ferida, necessitando tratamento cirúrgico, curativos e que traz problemas físicos, econômicos e familiares. Sobre seus cuidadores descreveram demonstração de atitudes e comportamentos mais negativos que positivos. A necessidade de melhor treinamento de seus cuidadores tanto nos aspectos cognitivos e psicomotor quanto afetivo, ficou evidente.

PALAVRAS-CRAVE: Doença de Fournier. Percepção. Fasciite necrosante.

\section{ABSTRACT}

The purpose of the present investigation was to identify the perception of the Fournier syndrome's patients about their disease and caregivers- Data was collected by means of interviews with a structured routine and the analysis was based on the Andres analysis of prose. According to the patients, the syndrome causes intense pain, edema, fever and wounds, demanding surgical treatment, dressings and bringing physical, economical and familiar problems. The caregivers' attitudes and behaviors were described as having more negative aspects than good ones. The necessity of a better training of the caregivers in the cognitive, psychomotor and affective sense is evident.

KEYWORDS: Fournier gangrene. Perception. Necrotizing fasciitis.

\section{RESUMEN}

El propósito de la presente investigación fue identificar la percepción de los pacientes que tuvieron el Síndrome de Fournier (SF) sobre esa afección, así como acerca de sus cuidadores. Los datos fueron colectados a través de entrevista con formulário estructurado y análisis basado en el Análisis de Prosa de André. Según los entrevistados, el SF causa dolor intenso, edema, fiebre y heridas, que necesitan de tratamiento quirúrgic y curativos ocasionando problemas físicos, económicos y familiares. Sobre sus cuidadores, describieron la demostración de actitudes y comportamientos más negativos que positivos. La necesidad de un entrenamiento mejor de sus cuidadores tanto en los aspectos cognitivos y psicomotores como afectivos, fue evidente.

PALABRAS -CLAVE: Gangrena de Fournier. Percepción. Fascitis necrosante.

\footnotetext{
* Enfermeira do Programa de Saúde da Família do Município de Elias Fausto-SP.

** Enfermeira, Professora Doutora do Curso de Enfermagem do Centro Universitário Barão de Mauá-Ribeiro Preto-SP, Professor Titular da Escola de enfermagem de Ribeirão Preto da Universidade de São Paulo (aposentada).
} 


\section{INTRODUÇÃO}

Algumas doenças devido alterações fisicas que causam ao seu portador, como deformidades, tumores e feridas, bem como distúrbios da mente e transmissão de doença infecciosas, podem provocar reações das mais diversas às pessoas, como rejeição, curiosidade, medo, pena, fuga, agressividade entre outras.Essas reações, remontam à própria história da humanidade, como podem ser observadas nas descrições da bíblia, nos filmes épicos e na literatura que descrevem ou caracterizam o comportamento dos povos antigos. Um exemplo típico a ser citado é o comportamento dos indivíduos com relação ao portador do Micobacterium leprae.

Apesar de todo o desenvolvimento científico e tecnológico dos dias atuais e já em pleno século XXI, ainda encontram-se pessoas com comportamentos e atitudes como os acima mencionados diante de algumas situações ou fatos. A aids, por exemplo, provocou, principalmente, no início de sua epidemia década de 80 - diversas reações de rejeição ao seu portador não somente da população em geral, mas inclusive do pessoal da área de saúde.

A Sindrome de Fournier, também se enquadra neste tipo de doenças estigmatizantes. Ela é descrita como uma afecção rara, todavia nos últimos anos tem sido observada com freqüência entre aqueles que procuram assistência à saúde. Trata-se de um processo infeccioso caracterizado por necrose do tecido subcutâneo e fáscia acompanhado por toxicidade sistêmica grave e gangrena progressiva da pele ${ }^{(1-3)}$.

A fascite necrosante é conhecida desde a Antigüidade como ficam evidenciadas nas descrições de Hipocrátes, Galeno, Avicena e Paré (4-5). Foi Fournier, em 1883, quem descreveu a infecção como gangrena idiopática fulminante que destrói rapidamente a genitália (6). Recebe o nome de Síndrome de Fournier quando o processo infeccioso acomete a região perineal, porém é também conhecida como fascite necrosante do períneo, gangrena escrotal, celulite necrosante sinérgica, gangrena sinérgica, gangrena idiopática, gangrena fulminante(6-40).

Esta afecção que se localiza na região perineal e adjacências com presença de dor, febre, edema e que evolui para necrose é um quadro dramático até mesmo para os profissionais da área de saúde.

Buscando na literatura científica, subsídios para fundamentar a assistência de enfermagem aos portadores desta síndrome, verificou-se diversas descrições e orientações nos seus aspectos da fisiopatologia, diagnóstico e tratamento, no entanto, notou-se uma lacuna no tocante aos aspectos psicossociais que esta enfermidade causa aos seus portadores.

Diante do exposto e motivado com a temática, decidiu-se realizar o presente estudo com a finalidade de obter elementos para a compreensão dos aspectos biopsicossociais do portador da sindrome de Fournier e assim poder fundamentar a assistência de enfermagem aos seus portadores.

\section{OBJETIVOS}

Este estudo teve como objetivo identificar a percepção dos pacientes que tiveram a Síndrome de Fournier sobre esta afecção, bem como a percepção dos mesmos sobre seus cuidadores.

\section{METODOLOGIA}

Trata-se de um estudo qualitativo do tipo retrospectivo expo-facto, cuja coleta de dados foi feita através de entrevista estruturada com registro cursivo, optando pelo método qualitativo de análise, tomando como orientação a Análise de Prosa de André". A Análise de Prosa é uma forma de investigação do significado dos dados qualitativos, um meio de levantar questões sobre o conteúdo de um determinado material, tais como: "o que é que este diz"; "o que significa"; "quais são as suas mensagens", incluindo as mensagens intencionais e não intencionais, explícitas ou implícitas, verbais ou não verbais, alternativas ou contraditórias. O primeiro passo da análise qualitativa é a construção de um sistema de categorias através do exame do material coletado, procurando identificar os tópicos, temas e padrões relevantes, caracterizando o tópico como um assunto e o tema como uma idéia. Os temas envolvem um nivel de abstração maior que os tópicos. Embora deva haver um critério para determinar o grau de importância de um tópico ou um tema, a subjetividade e a intuição têm um papel relevante para a localização de um dado, incluindo evidentemente, o quadro teórico no qual está situado o estudo. Outros pontos destacados pela autora supra citada são: considerar que o primeiro aspecto é que a análise está presente nos diferentes estágios da investigação e é parte integrante do processo de coleta de dados; levar em consideração que existe a compreensão ampla e profunda do objeto focalizado e que para isso são escolhidos certos tipos de dados que supostamente levarão à representação aproximada da realidade, e lembrar que os dados são obtidos pelo transitar constante do pesquisador entre a realidade e a teoria, num processo contínuo de inferências sobre o que os dados significam, o que implicam e para onde levam.

População: indivíduos que passaram pela experiência de terem sido portadores da Síndrome de Fournier, diagnosticados, tratados e com seguimento ambulatorial em um Hospital Escola do interior do Estado de São Paulo. 
Sujeitos do estudo: a amostragem foi intencional, ou seja, que atendessem ao seguinte critério de inclusão: serem moradores na mesma cidade do Hospital Escola em que receberam tratamento e acompanhamento clínico e estarem em condições de responder à entrevista.

De uma lista de 35 pacientes, cedida por um médico pesquisador do local de estudo, oito (8) atendiam ao critério proposto para este estudo. Porém foi excluído da amostra um jovem de 16 anos que foi portador da doença aos seis anos de idade, por se acreditar na dificuldade em relatar sua percepção em relação à doença, nessa fase da vida.

Procedimento. Os dados foram coletados através de entrevistas com auxilio de um roteiro estruturado e registro cursivo. O roteiro constou de três partes: a primeira com a identificação pessoal, a segunda com dados referentes à enfermidade e a terceira sobre a percepção do portador sobre a doença e seus cuidadores. Este passou pela análise de dois pesquisadores que verificaram a adequacidade e a confiabilidade do instrumento.
As entrevistas foram previamente agendadas através de telefonemas momento no qual foram esclarecidos os objetivos da pesquisa, assegurando inclusive o anonimato dos sujeitos deste estudo.

Antes da entrevista foram reforçados os propósitos da pesquisa e a garantia da manutenção do sigilo dos entrevistados, sendo realizada apenas com a anuência do paciente, atendendo a Resolução 196/96 sobre pesquisa com seres humanos.

\section{RESULTADOS E DISCUSSÕES}

Participaram deste estudo sete indivíduos que passaram pela experiência de terem sido portadores da Síndrome de Fournier, cuja escolha foi intencional atendendo ao critério de receberem tratamento e acompanhamentos clínico no Hospital Escola do interior do Estado de São Paulo e residirem nesta cidade. A caracterização dos sujeitos, deste estudo, encontram-se na tabela 1.

Tabela1 - Caracterização dos entrevistados, segundo idade, cor, estado civil, grau de instrução, ocupação. 2001.

\begin{tabular}{|c|c|c|c|c|c|c|}
\hline $\begin{array}{c}\text { Entrevistado } \\
\text { (E) }\end{array}$ & Idade & Cor & Sexo & $\begin{array}{c}\text { Estado } \\
\text { civil }\end{array}$ & $\begin{array}{c}\text { Grau de } \\
\text { instrução }\end{array}$ & Ocupação/profissão \\
\hline 1 & 65 & $\mathrm{~B}$ & $\mathrm{M}$ & $\mathrm{S}$ & IGC & Lustrador de móveis \\
\hline 2 & 72 & $\mathrm{~N}$ & $\mathrm{M}$ & $\mathrm{C}$ & $\mathrm{A}$ & Motorista de caminhão \\
\hline 3 & 66 & $\mathrm{~B}$ & $\mathrm{M}$ & $\mathrm{S}$ & $\mathrm{IGC}$ & Motorista de caminhão \\
\hline 4 & 80 & $\mathrm{~B}$ & $\mathrm{M}$ & $\mathrm{S}$ & IIGC & Professor aposentado \\
\hline 5 & 78 & $\mathrm{~B}$ & $\mathrm{M}$ & $\mathrm{C}$ & IGI & Trabalhador braçal \\
\hline 6 & 55 & $\mathrm{~B}$ & $\mathrm{M}$ & $\mathrm{C}$ & IGC & Mecânico \\
\hline 7 & 65 & $\mathrm{~B}$ & $\mathrm{M}$ & $\mathrm{C}$ & IGI & Comerciante \\
\hline
\end{tabular}

Legenda: B-branco N-negro

IGI-I grau incompleto

Esta síndrome não acomete somente as pessoas do sexo masculino, pois na literatura são citados vários casos entre mulheres e inclusive crianças $(7,10,12,13)$ Embora quase a totalidade dos sujeitos deste estudo seja de cor branca, não foram encontradas na literatura descrições sobre a relação da cor com a sindrome.

Quanto ao grau de instrução dos sujeitos verificou-se que quase a totalidade apresenta pouca escolaridade, justificada possivelmente por serem clientes de um Hospital Escola.

No que se refere aos dados sobre a Síndrome de Fournier verificou-se que os sujeitos do estudo haviam passado pela experiência da doença no máximo há cinco anos.

A percepção, dos pacientes sobre a Síndrome de Fournier está descrita a seguir.
S-solteiro C-casado A- analfabeto

IIGC-II grau completo

\section{Descrição dos sinais e sintomas e a localização...}

Tal como descrito na literatura os entrevistados (E) que passaram pela experiência de terem sido portadores da Sindrome de Fournier, deixam claro que é um quadro dramático de início insidioso, cuja dor é insuportável, com quadro de febre, edema e ferida caracterizada por necrose do tecido.

\footnotetext{
"... estava com muita febre, mal estar e muita dor... "(El)

"...aquilo doía muito(...) parecia que ia desmaiar..." (E 2)

"...lá atrás estava tudo inchado, vermelho e com uns pontinhos pretos... queimando... foi bem lá no buraco " (E 3).
} 
"...o pênis também... estava tudo necrosado ... a pele ficou inchada $e$ começou a ficar escura..." (E4)

..tive um mal estar muito grande...parecia que tinha um travesseiro no meio das pernas ...emagreci $10 \mathrm{Kg} \mathrm{em} 3$ dias ... "(E7)

Os sinais e sintomas mais evidentes são desconforto escrotal evoluindo para sensações dolorosas, mal estar, febre alta acompanhada de calafrios e sudorese. É comum no início, um discreto edema sem lesão aparente podendo ou não estar evidente os sinais clássicos de inflamação local, porém, com o desenvolvimento da doença ocorre áreas de enduração da derme, eritema, formação de bolhas permitindo que a infecção se espalhe pela fáscia, progredindo para ferida e necrose(14).

Em um estudo realizado em pacientes com diagnóstico de Sindrome de Fournier encontraram os seguintes resultados em termos de freqüência de sinais e sintomas: dor $100 \%$; eritema $100 \%$; febre $72 \%$; crepitação $62 \%$; choque $40 \%$; alteração do estado mental 32\% (4'. Com o passar do tempo a manifestação da gangrena é evidenciada por manchas escuras na pele, creptação e odor fétido, demonstrando a fase progressiva da gangrena ${ }^{(2,3,15)}$

Nesta síndrome, a secreção é formada por um líquido mais fluido, de coloração marrom escuro e cheiro característico e não pelo pus cremoso comum aos abscessos $\left({ }^{10}\right)$. Nesta fase da doença há a deterioração rápida do estado geral, tornando a ferida do músculo extensa e profunda, o que agrava a infecção do períneo.

Alguns autores referem que o desenvolvimento da necrose é secundário a uma endarterite obliterante, levando a trombose vascular cutânea, tornando possivel a entrada da flora normal da pele $\left({ }^{16}\right.$. A medida que ocorre a disseminação de bactérias aeróbias e anaeróbias a concentração de oxigênio nos tecidos é reduzida; com hipóxia e isquemia tecidual o metabolismo fica prejudicado, provocando uma maior disseminação de microrganismos facultativos, que se beneficiam das fontes energéticas das células formando gases (hidrogênio e nitrogênio) responsáveis pela crepitação, demonstrado nas primeiras 48-72 horas de infecção(17,16)

\section{Descrição de como surgiu...}

"...no início é interno"(E2)

"...era uma picadinha bem lá no fundo do osso".(E3)

"...a bolsa escrotal começou a inchar, inchar... uma dorzinha que foi aumentando..." (E4)

•"..Foi de uma hora para outra." (E7)

\section{Descrição da extensão da ferida...}

"...foi inchando e apodrecendo tudo "(E3)

"...um lado da nádega estava todo inchado, vermelho (...) depois passou para outra nádega ". (E5)

"...começou na virilha depois pegou quase toda região." (E6)

"...cabia a mão dentro do buraco... "(E7)

Descrição do tratamento...

"...fiz implante de pele... tive que fazer cirurgia "(E3)

"...foram obrigados a fazer quatro grandes cortes em volta do ânus... teve que raspar o osso, nervo.. ". (E5)

"...foi limpeza cirúrgica...aplicou voltarem para dormir a noite... "(E7)

\section{Descrição do Curativo...}

"...a pior hora era a do curativo... Os curativos eram diários... feitos pelos residentes... umas quatro vezes ao dia e só ... eles me arrancavam pedaço "(E4)

"Era o enfermeiro quem fazia duas vezes o curativo... eu fiz umas oito (8) ou dez (10) limpeza, todas com anestesia "(E5)

"...lavar com água e sabão... os curativos eram terriveis "(E6

\section{Descrição da evolução da Sindrome de Fournier...}

No momento da entrevista nenhum dos entrevistados apresentava mais a sindrome de Fournier, porém houve relato de sequelas

"Se passar do tempo sem ir ao banheiro faço na roupa e sujo tudo" (E2)

"...não seguro mais...o ânus ficou pendurado e agora não posso mais fazer movimentos... eles foram obrigados a cortar tudo em volta do ânus...tiraram os nervos, então não seguro...tenho dificuldade de fazer xixi porque, tenho que fazer como uma mulher... Ficou três fistula na uretra..." (E3).

\section{Descrição da causa da doença...}

"Não sei, nem sonho, nem tenho a menor noção do que é isso ". (E2) 
"...foi um tombo...eu acho que foi o peso... não sei o que pode ter causado a doença, talvez pela hemorróidas ou pelo... uso de supositório... Antes da ferida eu tive gonorréia, sifilis e cancro... Tinha também hemorróidas... nesse calor ... pode dar hemorróidas...essa doença é muito comum nos caminhoneiros...que pode ter causado é sentar em banco quente no carro." (E3)

"...tinha uma fissura no ânus e que pode ter sido onde tudo começou ". (E4)

Devido o caráter obscuro da etiologia da Sindrome de Fournier, no passado, esta era considerada de origem idiopática. Atualmente, 35\% dos casos desta patologia tem etiologia na região anorretal (hemorróidas, fistula e abscesso) e práticas sexuais como coito, anal(10). Alguns autores descrevem causa urológica como orquite, hidrocele, vasectomia, sondagem vesical e instrumentação urológica(19), além de câncer de bexiga, epididimite, balanite, retenção urinária, implantação de próteses perineais ${ }^{(4,10)}$ Esta patologia pode estender-se à parede abdominal(20) e até axilas.

Há também na literatura relato de casos da doença pós-cirurgias e métodos invasivos de herniorrafia, apendicectomia, diverticulectomia, hemorroidectomia, orquiectomia, vasectomia, circuncisão e biópsia prostática $(4,10)$, após traumas (perineal, sexual), picada de insetos, mordida humana, corpo estranho (osso de frango, espinho de peixe), e ainda 20 a 30\% dos casos de origem idiopática. Acredita-se que em indivíduos imunodeprimidos, com diabetes mélitos, alcoolismo crônico, insuficiência hepática e renal, hipertensão arterial, câncer, dentre outros, possam ter maior suscetibilidade a essa sindrome(10).

A análise laboratorial do material colhido da região infectada mostra múltiplos microrganismos aeróbios e anaeróbios sugerindo hipótese de sinergismo (4).

Os agentes etiológicos mais comumente encontrados são Streptococus, Stafilococus e microrganismos Gram negativos, Bacteroides(15), Klebsiella, Proteus, E. coli, Pseudomonas(4,6) e Clostridium(15).

As infecções anorretais, muitas vezes são devido a agentes anaeróbios produtores de gás. Os diferentes microrganismos encontrados nas culturas são originário da uretra, reto ou pele(4).

\section{Descrição da existência de outras patologias,} uso de drogas, bebidas alcoólicas...

"...bebo de 4 a 5 litros de pinga por dia...". (E1)

".. já bebi".(E2)

'Antes eu tive gonorréia, sifilis e cancro, tinha também hemorróidas..." (E3)

\section{Descrição da duração da doença/ internação ...}

"...fiquei 44 dias na Unidade de Emergência e 31 no Campos ". (E 3)

"...mais de seis meses ". (E6)

"...fiquei mais um mês fazendo tratamento que ele falou ". (E7)

\section{Descrição de outros problemas...}

"... um dos motivos de ter abandonado o tratamento (...) foi a demora dos retornos (...) cada vez era atendido por uma pessoa diferente que não acompanhava o caso". (E 3)

"...procurei o convênio porque ia ficar muito caro ". (E 4)

"... a minha mulher estava morrendo de medo ". (E4)

"Era uma tristeza muito grande em casa".(E5)

"...vivia brigando para me dar remédio..." (E6)

"Financeiramente ficamos muito prejudicado." (E 7)

Analisando em seu conjunto, a percepção dos entrevistados no tocante à SF, pode-se verificar que estes fazem referência à mesma, tal como os descritos na literatura.

Em relação a percepção sobre seus cuidadores os entrevistados deste estudo, que passaram pela experiência de terem sido portadores dá Síndrome de Fournier, descreveram atitudes e comportamentos tantos positivos quanto negativos.

\section{Descrição da percepção de atitudes e comportamentos positivos...}

\section{De dedicação...}

'A minha mulher fazia os curativos. (E6)

"A dedicação do Dr ... foi tão grande, mas tão grande que eu acho que foi isso que me curou." (E7) De encorajamento...

"...pedia para que eu tivesse força e acreditasse em Deus".(E7)

"...tentaram me animar..." (E7)

\section{De ajuda/cooperação...}

"...fui internado e operado"(E3)

"Eu tenho diabetes e hipertensão..." (E6) 
"Eram os enfermeiros que faziam o curativo. O local não poderia ficar sujo um minutinho ...fiquei quatro dias internado, para não pegar infecção..." (E6)

\section{De orientação...}

"...o enfermeiro ensinou a minha mulher a fazer os curativos..." (E6)

\section{Descrição das atitudes e comportamentos negativos...}

\section{De medo/ horror...}

"...disse: ... a mão cabia dentro do buraco, já pensou que horror". (E 6) .

"...ouvi ... o que é isso?" (E7)

\section{De omissão...}

"Porque ninguém falava nada ". (E2)

\section{De pena...}

"..falava baixinho, que dó." (E4)

"...falavam, coitado, que pena..." (E5) De

desespero...

"Tinha uma mocinha que entrou no quarto para ver ...sua cara era de desespero ". (E7)

De espanto...

"... ficavam todos espantados de ver o

$\mathrm{O}$

desenvolvimento da doença "(E 6)

gravidade... De

"...ouvi ... o caso dele é muito grave".(E 5)

...o médico falou se sair outra vez é cemitério ". (E6) "...disseram, quem vai para cirurgia dificilmente sai da mesa..." (E6)

De curiosidade...

"...teve muita gente tirando foto ..." (E6) "...até mesmo os médicos de outro setor iam lá ver... ". (E7)

De morte ou fim próximo... "...tinham quase certeza que eu ia morrer". (E 6)

"...Eu_olhava para eles e via eles pensavam que era o meu fim ". (E6)

\section{De brutalidade...}

"...foram me colocar na cama, mas foram estúpidos... ". (E6)

\section{De dificuldade de cuidar...}

"...estourou todas as veias para colocar o soro".(E 4)

"...tinha um que tinha prática, outro não".(E6)

De descaso...

"...deveria ter um responsável...". (E4)

\section{De desconhecimento das patologias...}

"...examinou e disse que vinha a furo um furúnculo ". (E4)

"...os médicos do convênio não conheceram a doença". (E4)

"...o médico disse que era hemorróidas (...) fui na farmácia e o farmacêutico falou que não era".(E4)

...espremeram e daí danô tudo ". (E5 ) "...falavam

tá com câncer vai morrer". (E6 ) 
perda de emprego, dificuldades econômicas para o sustento da família e a possibilidade de incapacidade permanente; a vergonha da doença e o medo de serem rejeitados por serem portadores de doença estigmatizante. "O primeiro contato com o paciente e seus familiares, a maneira como são recebidos é decisiva para um bom relacionamento e entrosamento com o paciente e sua família" (23). Um aspecto que merece reflexão, neste estudo, foi a detecção de atitudes e comportamentos negativos que podem influir no relacionamento e conseqüentemente no restabelecimento do paciente. Ficou evidente que muitos destes profissionais não estão instrumentalizados para dar assistência ao paciente de forma adequada. Freqüentemente o paciente expressa somente ao enfermeiro seus receios e pressentimentos.

É de suma importância, portanto, a interação do enfermeiro com o paciente. Nessa interação é necessário encorajar a verbalização, ouvir, saber compreender e proporcionar informações que ajudem a minimizar as preocupações, os medos, as inseguranças e as fantasias.

\section{CONCLUSÃO}

A Sindrome de Fournier é uma ameaça significativa à vida do indivíduo; causa dor insuportável, edema, febre, ferida, necessitando tratamento cirúrgico e curativos dolorosos, traz problemas fisicos (fistulas urinária e relaxamento do esfincter anorretal), econômico e familiares. Sua qualidade de vida fica profundamente prejudicada em decorrência de sua patologia.

O estudo mostrou que os pacientes fazem referência à doença tal como descrito na literatura, no tocante aos sinais e sintomas, tratamento, localização, duração e evolução da doença, todavia ficou evidenciado a falta de orientação aos pacientes pelos seus cuidadores sobre a causas e medidas preventivas.

A percepção que os pacientes tiveram de seus cuidadores foram tanto de atitudes e comportamentos positivos quanta de negativos, porém superando estes últimos. Dentre os positivos descreveram de dedicação, de encorajamento, de ajuda, de cooperação. Entre os negativos foram de medo, horror, de pena, de desespero, de espanto, de gravidade, de curiosidade, de morte ou fim próximo, de brutalidade, de dificuldade para cuidar, de descaso, de desconhecimento da patologia.

Assim, neste estudo fica evidente a necessidade dos cuidadores estarem melhor instrumentalizados tanto nos aspectos cognitivos quanto psicomotor e afetivo, para que possam promover uma assistência mais profissional e humana.

\section{REFERENCIAS BIBLIOGRÁFICAS}

(1) Janevicius RV, Hann SE, Batt MD. Necrotizing fasciitis. Surg Ginecol Obstet 1982; 154(2): 97-102.
(2) Iorianni P. Oliver G C. Synergistie soft tissue infections of the perineum. Dis. Colon Rectum 1992; 35(5):640-44.

(3) Shupak A, Shoshani O, Gpldenberg I, Barzilai A, Moskuna R, Bursztein S.. Necrotizing fasciitis-. a indication for hyperbaric oxygenation therapy. Surgery 1995; 118(5):873-8.

(4) Pajecki D. Sindrome de Fournier: conceitos diagnósticos e terapêuticos. Rev Med 1994; 73(1):43-55.

(5) Pessa ME, Howard RJ. Necrotizing fasciitis. Surg Gynecol Obstet 1995; 161(4):357-61.

(6) Wang LE Wong HY, Griffith DE Ercole C.- What happened down there? Fournier's gangrene- Urologic Nursing 1997; 17(1):29-32.

(7) Redman J F, Yamauchi T, Higginbothon WEI. Fournier's gangrene of the serctum in a child J Urol $1979 ; 121(6): 827$.

(8) Flanigan RC. Diagnosis and treatment of gangreneous genitalia. Surg Clin North Am 1984; 64(4):715-20.

(9) Andrade ACH, Amarante MTJ, Ferreira MC, Lodovici O. Cirurgia reparadora na seqüela da Sindrome de Fournier. AMB Rev Assoc Med Bras 1991jan-mar; 37(1): 22-6.

(10) Guimarães AS, Feres O, Aprilli F, Rocha JJR. Sindrome de Fournier. Medicina 1995 out-dez; 28(4): 722- 4.

(11)André MEDA. Texto contexto e significados: algumas questões na análise de dados qualitativos. Cad Pesq 1983; 45:66-71.

(12) Lauks SS. Fournier's gangrene. Surg Clin North Am 1994; 74(6):1339-52.

(13) Sawin RS, Schaller RT, Tapper D, Morgan A, Cahil J. Early recognition of neonatal abdominal wall necrotizing fasciitis. Am Journal Surgery 1994; 167(4): 481-4.

(14) Van Brien P, Mattelaer J, Billiet I. Fournier's gangrene: report of three case and review of the literature. Acta Urologica Belga 1990; 58(2):161-169.

(15) Hutzler RN. Gangrena gasosa. In: Veronesi R, editor. Doenças infecciosas e parasitária. $8^{a}$ ed. Rio de Janeiro: Guanabara Koogan; 1991. p.443-6.

(16) Enriquez JM, Moreno S, Devesa M, Morales V, Platas A, Vicente E. Fournier's Syndrome of urogenital and anoretal. Dis Colon Rectum 1987; 30(1):33-7.

(17) Burpee JF, Edwards P Fournier's gangrene. J Urol 1972; 107(1/6):812-4.

(18) Brown GS, Jones RB, Hirschimann JN. Fournier's gangrene-necrotizing subcutaneous infection of the male genitalia. J Urol 1979; 122(116):279-82.

(19) Viddleer AC, Nijeholt GAB. Lethal Fournier's gangrene following vasectomy. J Urol 1992; 147(3):1613-4.

(20) Hartnett J.M. Fournier's gangrene-Assessment and management. Critical Care Nurse 1995; 15(6): 14-5.

(21) Rodrigues A. Psicologia social. 12 ed. Rio de Janeiro: Vozes, 1988.

(22) SaranoYO. relacionamento com doente. São Paulo: EPU, 1978

(23) Minzoni MA. Assistência de enfermagem ao doente mental. Ribeirão Preto: Guarani; 1974

\section{Artigo recebido em 19/04/01}

\section{Artigo aprovado em 19/09/01}

